\title{
Utilização de inteligência artificial (redes neurais artificiais) para a classificação do comportamento bioquímico de amostras de Escherichia coli isoladas de frangos de corte*
}

\author{
The use of artificial intelligence (artificial neural networks) to classify the biochemical \\ reactions of Escherichia coli isolates from broilers
}

\begin{abstract}
Felipe de Oliveira Salle', Flávia Bonarcini Borges Fortes', Ana Cristina Gonçalves Pinto da Rocha², Silvio Luis da Silveira Rocha', Guilherme Fonseca de Souza', Hamilton Luiz de Souza Moraes', Lucas Brunelli de Moraes ${ }^{1} \&$ Carlos Tadeu Pippi Salle ${ }^{1}$
\end{abstract}

\begin{abstract}
RESUMO
A Escherichia coli é comumente encontrada na avicultura e muitas vezes sua presença no organismo dos animais e/ou contaminando as camas de aviários não causa estranheza. Por outro lado, a utilização de inteligência artificial, especificamente redes neurais artificiais, está sendo crescentemente empregada como ferramenta para medir relações não lineares entre variáveis. Neste trabalho foram usados os dados disponíveis referentes a 261 amostras da bactéria oriundas de camas de aviários, lesões de celulite e quadros respiratórios de frangos de corte. O diagnóstico laboratorial envolveu o isolamento do agente, a caracterização dos genes associados à virulência, as lesões provocadas pela inoculação em pintos, o Índice de Patogenicidade das amostras e a resistência antimicrobiana a 14 antibióticos que foram as entradas das redes neurais e sete provas bioquímicas as saídas. A principal conclusão deste artigo foi de que as redes neurais foram capazes de realizar a classificação correta do comportamento das amostras com amplitude de $87,80 \%$ a $98,37 \%$. A sensibilidade e a especificidade das classificações obtidas variaram de $59,32 \%$ a $99,47 \%$ e de $80,00 \%$ a $98,54 \%$, respectivamente.
\end{abstract}

Descritores: Escherichia coli, bioquimismo, redes neurais artificiais.

\section{ABSTRACT}

The Escherichia coli is often found in the poultry industry and, many times, its presence in the organism of the animals and/or contaminating the litter of poultry houses don't cause surprise. On the other hand, the use of artificial intelligence, specifically, artificial neural network, is being increasingly used as tool to measure not linear relations between variables. In this work we used available data from 261 samples of the bacterium isolated of poultry litter, lesions of cellulitis and respiratory problems of broilers. The laboratory diagnosis involved the isolation of the agent, the characterization of the genes associates with the virulence, the lesions provoked by the inoculation in day-old-chicks, the Pathogenicity Index of the samples and the antimicrobial resistance against 14 antibiotics. Those variables were the inputs of the neural network and the outputs were seven biochemical tests. The main conclusion of this paper was that the neural network were capable to make correct classification of the biochemical reactions of all the samples with amplitude from $87.80 \%$ to $98.37 \%$. The sensitivity and the specificity of the classifications varied from $59.32 \%$ to $99.47 \%$ and from $80.00 \%$ to $98.54 \%$, respectively.

Keywords: Escherichia coli, biochemical reactions, artificial neural network.

*Trabalho originado da Tese do primeiro autor. Programa de Pós-graduação em Ciências Veterinárias (PPGCV), Universidade Federal do Rio Grande do Sul (UFRGS), Porto Alegre, RS, Brasil. ${ }^{1}$ Centro de Diagnóstico e Pesquisa em Patologia Veterinária (CDPA), Departamento de Medicina Animal, Faculdade de Veterinária, UFRGS, Av. Bento Gonçalves no. 8824, CEP 91540-00 Porto Alegre, Rio Grande do Sul, Brasil. ${ }^{2}$ Coordenação Geral de Apoio Laboratorial, Secretaria de Defesa Agropecuária, Ministério da Agricultura, Pecuária e Abastecimento, Brasília, DF, Brasil. CORRESPONDÊNCIA: F.O. Salle [sallefelipe@ gmail.com - FAX + 55 (51) 3319-1062]. 


\section{INTRODUÇÃO}

As redes neurais artificiais consistem em um método de solucionar problemas e, diferentemente dos sistemas convencionais, aprendem, executam operações não lógicas, descobrem as relações ou regras dos dados e exemplos e testam todas as possibilidades em paralelo. A rede neural se baseia nos dados disponíveis para extrair um modelo geral [5]. No entanto, o sistema deve ser alimentado com dados reais que permita seu treinamento e aprendizado. Assim, ela é capaz de extrair regras básicas a partir de dados reais [1]

A Escherichia coli é um microorganismo conhecido por causar doenças em aves, embora ainda não esteja claro se é uma causadora primária ou secundária das enfermidades a ela atribuídas [3]. Os mecanismos de virulência das amostras de E. coli potencialmente patogênicas para aves (APEC) tem sido continuamente estudados e acredita-se serem multifatoriais.

Recentemente, Fortes [2] estudou o comportamento bioquímico de 261 amostras de $E$. coli isoladas de aves. Os resultados obtidos demonstraram que as amostras positivas para arginina, dulcitol, rafinose e sacarose têm maiores Índices de Patogenicidade (IP) que as negativas. Já as amostras negativas para a salicina e para o teste de indol também possuem IP mais altos que as positivas. Também concluiu que a salicina, a sacarose, a rafinose, o adonitol e o dulcitol, bem como a arginina e a ornitina apresentaram resultados variáveis para $E$. coli.

O objetivo do trabalho foi construir redes neurais artificiais para predizer os resultados dos testes bioquímicos variáveis relatados por Fortes [2]. Como entradas, utilizaram-se informações já existentes ou novas. Neste último caso está a resistência antimicrobiana [4].

\section{MATERIAIS E MÉTODOS}

Os dados utilizados no presente trabalho estão reunidos num banco de dados gerado no Centro de Diagnóstico e Pesquisa em Patologia Aviária (CDPA), Faculdade de Veterinária, Universidade Federal do Rio Grande do Sul. Utilizaram-se informações sobre 261 amostras de Escherichia coli tais como: características bioquímicas; índices de patogenicidade; lesões provocadas pela inoculação em pintos de um dia (celulite, peritonite, periepatite, peri- cardite e aerossaculite); caracterização dos genes associados à patogenicidade; resistência antimicrobiana a 14 antibióticos (Amicacina, Amoxacilina e Ácido clavulânico, Ampicilina, Cefalexina, Cefuroxina, Ceftiofur, Ciprofloxacina, Clindamicina, Cotrimoxazol, Enrofloxacina, Gentamicina, Norfloxacina, Ofloxacina, Tetraciclina); origem das amostras (cama de aviário, celulite e quadros respiratórios); e motilidade bacteriana.

As redes neurais artificiais foram construídas utilizando-se o software Neuroshell Classifier 2.1 (Ward Systems Group, Inc., Frederick, MD, USA, 1997-2000).

Os resultados disponíveis foram transformados de forma binária. Assim sendo os resultados negativos são representados pelo número $0 \mathrm{e}$ os positivos pelo 1. Este critério foi utilizado para a sensibilidade (0) ou resistência (1) aos 14 antibióticos estudados, à ausência (0) ou presença (1) dos genes associados à patogenicidade, à ausência (0) ou presença (1) das distintas lesões observadas nos pintos. As amostras imóveis foram representadas pelo 0 e as móveis pelo 1. No caso da origem das amostras, houve a necessidade de acrescentar mais um valor e a anotação dos dados foi a seguinte: cama (0), celulite (1) e quadros respiratórios (2)

Resumidamente, a rede começa tentando encontrar relações lineares entre as entradas e as saídas. São atribuídos pesos às ligações entre os "neurônios" de entrada e de saída. Feito isto, são adicionados neurônios na camada oculta (no presente trabalho foram usadas 80 camadas) para que relações não lineares sejam encontradas. Os valores de entrada na primeira camada são multiplicados pelos pesos e passados para a segunda camada (oculta). Os neurônios da camada oculta produzem valores que são transmitidos para a camada de saída. Este resultado obtido na camada de saída é comparado com o resultado real e, se necessário, novas camadas ocultas são adicionadas até a obtenção do resultado real, ou o mais próximo dele. Este procedimento se constitui no "aprendizado" da rede neural artificial e a validação se dará com dados que a rede neural desconhece, mas que estará apta a classificar corretamente.

As entradas escolhidas para a construção das redes neurais artificiais foram os índices de patogenididade, as lesões induzidas em pintos de um dia de 
idade, a caracterização dos genes associados à patogenicidade, a resistência antimicrobiana, a origem das amostras e a motilidade das amostras. As saídas foram as reações bioquímicas variáveis obtidas por Fortes [2]: ornitina, arginina, adonitol, rafinose, sacarose, salicina e dulcitol.

\section{RESULTADOS}

Na Tabela 1 estão apresentadas as características das redes neurais artificiais construídas com as entradas Resistência antimicrobiana (Antib), Genes associados à patogenicidade (Gen), Índice de Patogenicidade (IP), Motilidade da E. coli (Motilid), Lesões produzidas em pintos de um dia (L) e Origem da amostra (O). As saídas são as distintas reações bioquímicas classificadas como variáveis estabelecidas por Fortes [2].

A Tabela 1 também revela que as redes neurais artificiais foram capazes de classificar com grande precisão o resultado positivo ou negativo de todos os testes bioquímicos estudados. O pior resultado, e ainda assim muito bom, foi o obtido para salicina, no qual as classificações corretas foram de $87,80 \%$, acompanhada de sensibilidade de $88 \%$ e de especificidade de $87,6 \%$. No outro extremo está a arginina, onde $98,37 \%$ das classificações estavam corretas e os valores da sensibilidade e da especificidade foram de $99,47 \%$ e $94,64 \%$, respectivamente. Os demais testes bioquímicos situam-se entre estes dois extremos, como pode ser observado, e atestam a capacidade das redes neurais classificarem os resultados dos testes bioquímicos a partir de informações disponíveis.
Na Figura 1 é apresentado exemplo de interface para a colocação dos dados de entrada, destinados a classificar a negatividade (0) ou positividade (1) para a arginina. Em razão da totalidade dos dados de entrada ultrapassar o espaço disponível nesta página, somente alguns valores estão aparentes. O resultado apresentado mostra que a amostra do exemplo é arginina positiva com $99,1 \%$ de probabilidade.

\section{CONCLUSÃO}

As redes neurais artificiais foram capazes de classificar as reações bioquímicas de 261 amostras de Escherichia coli a partir do conhecimento do índice de patogenicidade; das lesões provocadas pela inoculação em pintos de um dia; caracterização dos genes associados à patogenicidade, resistência antimicrobiana a 14 antibióticos, origem das amostras e da motilidade bacteriana

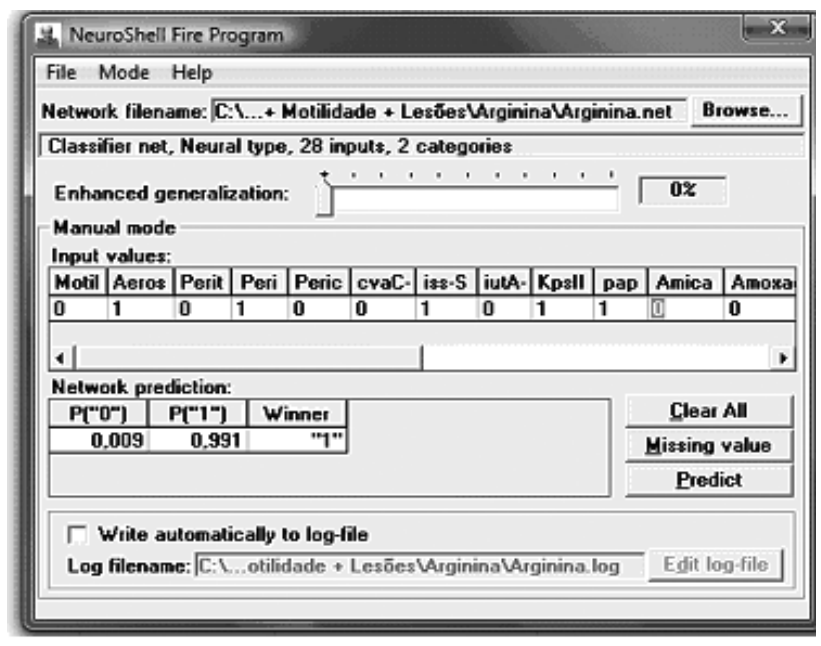

Figura 1. Interface para a colocação dos dados de entrada para a obtenção do resultado Negativo (0) ou Positivo (1) para a saída Arginina.

Tabela 1. Classificações das reações bioquímicas, positivas ou negativas, de 261 amostras de Escherichia coli, através do uso de redes neurais artificiais.

\begin{tabular}{ccccc}
\hline Saída & Entradas & Class. Corr. (\%) & Sens. & Esp. \\
\hline Adonitol & Antib + Gen + IP + Motilid + L + O & 94,72 & 0,9895 & 0,8000 \\
Arginina & Antib + Gen + IP + Motilid + L & 98,37 & 0,9947 & 0,9464 \\
Dulcitol & Antib + Gen + IP + Motilid + L + O & 94,31 & 0,7963 & 0,9844 \\
Ornitina & Antib + Gen + IP + Motilid + L & 90,24 & 0,5932 & 0,9519 \\
Rafinose & Antib + Gen + IP + Motilid + L & 96,34 & 0,8500 & 0,9854 \\
Sacarose & Antib + Gen + IP + Motilid + L + O & 90,65 & 0,8028 & 0,9486 \\
Salicina & Antib + Gen + IP + Motilid + L + O & 87,80 & 0,8800 & 0,876 \\
\hline
\end{tabular}




\section{REFERÊNCIAS}

1 Forsström J.J. \& Dalton K.J. 1995. Artificial neural networks for decision support in clinical medicine. Annals of Medicine. 27(5): 509-517.

2 Fortes F.B.B. 2008. Perfil bioquímico de 261 amostras de Escherichia coli isoladas de diferentes materiais de origem avícola no Estado do Rio Grande do Sul. 53f. Porto Alegre, RS. Dissertação (Mestrado em Ciências Veterinárias) - Faculdade Medicina Veterinária, Universidade Federal do Rio Grande do Sul.

3 Montgomery R.M., Jones L.S., Boyle C.R., Luo Y. \& Boyle J.A. 2005. The embryo lethality of Escherichia coli isolates and its relationship to various in vitro attributes. Avian Diseases. 49(1): 63-69.

4 Salle F.O. 2009. Utilização de inteligência artificial (redes neurais artificiais) para a classificação da resistência a antimicrobianos e do comportamento bioquímicode amostras de Escherichia coli isoladas de frangos de corte. 88f. Porto Alegre, RS. Tese (Doutorado em Ciências Veterinárias) - Programa de Pós-graduação em Ciências Veterinárias, Universidade Federal do Rio Grande do Sul.

5 Tatibana C.Y.; Kaetsu D.Y. 2004. Uma Introdução as Redes Neurais. [Fonte:<http://www.din.uem.br/ia/neurais>]. 